\title{
Medtronic submits full data on spinal protein to independent scrutiny
}

In this News article by Deborah Cohen (BMJ 2011;343:d5484, doi:10.1136/bmj.d5484) we said that Dr Harlan Krumholz will be heading a steering committee that will commission two organisations with expertise in conducting large systematic reviews to evaluate the data on recombinant bone morphogenetic protein 2 (rhBMP-2). Dr Krumholz has advised us, however, that the steering committee that "is advisory to this process will be chaired by Dr Ezekiel Emanuel, and the committee members will be chosen with his guidance to include many different perspectives and to provide a wide range of relevant experience and expertise."

Cite this as: BMJ 2011;343:d5687

๑ BMJ Publishing Group Ltd 2011 